\title{
Discordant Patterns of mtDNA and Ethno-Linguistic Variation in 14 Iranian Ethnic Groups
}

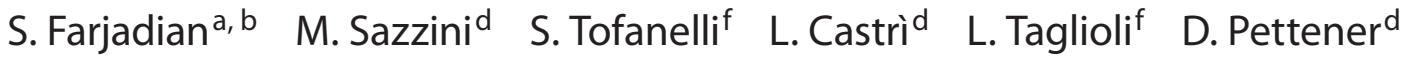 \\ A. Ghaderia,c G. Romeo ${ }^{\mathrm{e}}$ D. Luisellid

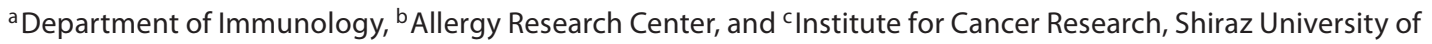 \\ Medical Sciences, Shiraz, Iran; ${ }^{\mathrm{d} D i p a r t i m e n t o ~ d i ~ B i o l o g i a ~ E v o l u z i o n i s t i c a ~ S p e r i m e n t a l e, ~ U n i v e r s i t a ̀ ~ d i ~ B o l o g n a, ~ a n d ~}$ \\ eUnità Operativa di Genetica Medica, Dipartimento di Scienze Ginecologiche, Ostetriche e Pediatriche, Policlinico \\ Sant'Orsola Malpighi, Università di Bologna, Bologna, and ${ }^{\mathrm{f}}$ Dipartimento di Biologia, Università di Pisa, Pisa, Italy
}

\section{Key Words}

mtDNA $\cdot$ Human population genetics $•$ Iranian ethnic groups

\begin{abstract}
Background/Aims: Present-day Iran has long represented a natural hub for the expansion of human genes and cultures. That being so, the overlapping of prehistoric and more recent demographic events interacting at different time scales with geographical and cultural barriers has yielded a tangled patchwork of anthropological types within this narrow area. This study aims to comprehensively evaluate this ethnic mosaic by depicting a fine-grained picture of the Iranian mitochondrial landscape. Methods: mtDNA variability at both HVS-I and coding regions was surveyed in 718 unrelated individuals belonging to 14 Iranian ethnic groups characterized by different languages, religions and patterns of subsistence. Results: A discordant pattern of high ethno-linguistic and low mtDNA heterogeneity was observed for the whole examined Iranian sample. Geographical factors and cultural/ linguistic differences actually represented barriers to matrilineal gene flow only for the Baloch, Lur from Yasouj, Zoroastrian and Jewish groups, for which unusual reduced levels of mtDNA variability and high inter-population distances
\end{abstract}

were found. Conclusion: Deep rooting genealogies and endogamy in a few of the examined ethnic groups might have preserved ancestral lineages that can be representative of Proto-Indo-Iranian or prehistoric mitochondrial profiles which survived relatively recent external contributions to the Iranian gene pool.

Copyright $\odot 2011$ S. Karger AG, Basel

\section{Introduction}

Present-day Iran occupies a pivotal geographical position within the South-Western Asian corridor, a natural passageway that has represented a tri-continental crossroad for human migrations since the first expansions of anatomically modern humans out of Africa [1]. Several studies have indeed proposed that sea level fluctuations in the Strait of Hormuz gave a boost to the diffusion of Homo sapiens populations from the Arabian Peninsula to the Iranian plateau and, from here, to Pakistan, India and Eastern Asia, during the early colonization of the Eurasian landmass [2-4]. As a matter of fact, Paleolithic sites have been recently discovered in Western [5] and Northern Iran (Central Alborz) [6], providing some of the first

\section{KARGER}

Fax +4161306 1234 E-Mail karger@karger.ch www.karger.com
(ㄷ) 2011 S. Karger AG, Basel

$0001-5652 / 11 / 0722-0073 \$ 38.00 / 0$

Accessible online at:

www.karger.com/hhe
Giovanni Romeo, Unità Operativa di Genetica Medica

Dipartimento di Scienze Ginecologiche, Ostetriche e Pediatriche

Policlinico Sant'Orsola Malpighi

Università di Bologna, via Massarenti 9, IT-40136 Bologna (Italy)

Tel. +39 051208 8420, E-Mail romeo@ eurogene.org 
field evidences of early human settlements in this central area of the Middle East.

Nevertheless, the Neolithic and Metal Ages seem to be the time windows that left the deepest imprint on the Iranian genetic landscape. Triggered by an abrupt shift towards warmer climate conditions following the Younger Dryas cold interval [7], new agricultural techniques appear to have been first developed about 8,500 YBP in the mid-level and lower valleys of the Zagros Mountains, especially in Elam (present South-Western Iran). Here, several local cultures speaking the Proto-Elamo-Dravidian language flourished in response to population increase [8], even maintaining smaller and more scattered familyscale organizations with respect to other geographical areas of agricultural development (i.e. Mesopotamia). A subsequent diffusion of these cultures eastwards occurred in parallel with the movement of farmers to the Indus Valley and the Indian subcontinent [9]. The Dravidian languages were then almost completely replaced around 1,300 BC by the Indo-Iranian branch of the IndoEuropean language family at the arrival of the Aryans, nomadic tribes currently considered plausible ancestors of most of the present Iranians [10]. Medes, Persians, Bactrians and Parthians thus populated the Iranian plateau by the 1st millennium BC. One of these tribes, the Medes, succeeded in unifying territories and people to such an extent that, under Cyrus the Great and Darius the Great (559-486 BC), the Persian Empire became one of the largest empires in human history. It has been speculated that after the Persian apogee, other population movements, following the invasions by the Macedonians (334 BC), the Arabs (7th century AD), the Turks (11th century AD), and the Mongols (13th-15th century AD), while largely contributing to the ethno-linguistic heterogeneity of the region, only marginally affected the pre-existent genetic pool [11].

According to this view, the Iranian corridor still hosts populations with very different backgrounds in terms of origins, languages, religions and modes of subsistence, even though the genetic diversity of few Iranian ethnic groups has been investigated so far [11-16]. In particular, mitochondrial diversity has been the object of either wide-ranging studies directed towards a generalized comparison between Western and Eastern Eurasian populations [11, 17], or research whose sampling criteria focused on the geographic origin rather than the ethnicity of the examined individuals [18-20]. Therefore, an assessment of the overall Iranian mtDNA landscape is still to be drawn. The present study surveyed the variability at the mtDNA HVS-I region of 718 unrelated Iranian indi- viduals from 14 ethnic groups belonging to three linguistic families, following four distinct religions and having different patterns of subsistence. It thus aims at improving our understanding of the genetic history of the different Iranian ethnic groups, the spread of Indo-European languages and the extent to which late Paleolithic populations, Neolithic farmers and more recent historical events have contributed to shape the current Iranian matrilineal gene pool.

\section{Subjects and Methods}

\section{Ethnic Group Samples}

A panel of 718 unrelated healthy Iranian individuals belonging to the following 14 different ethnic groups was analyzed: 61 Balochis (B) from Iranshahr; 23 Gilakis (G) from Rasht; $51 \mathrm{Ma}-$ zandaranis (M) from Sari; 53 Azeris (Az) from Tabriz; a total of 59 Lurs, 30 from Khoramabad $\left(\mathrm{L}_{1}\right)$ and 29 from Yasouj $\left(\mathrm{L}_{2}\right) ; 58$ Parsees (P) from Shiraz; 56 Jews (J) from Shiraz; 46 Qashqaees (Qa) from the Fars province; 52 Armenians (Ar) from Isfahan; 55 Turkmens (T) from Gonbad; 49 Zoroastrians (Z) from Yazd; 45 Arabs (Ab) from Ahvaz; 55 Kurds (K) from Saqqez; and 55 individuals from the Qeshm Island (Qe) (table 1, fig. 1).

All participants were third-generation natives from the selected geographical areas and all their retrospectively collected data were treated in an anonymous way. The research protocol was approved by the Shiraz University of Medical Sciences Ethics Committee (approval No. 81-32).

\section{HVS-I Sequence Analysis}

DNA was extracted from each blood sample using a standard salting-out method [21]. Variation at the mtDNA HVS-I region was investigated by sequencing a total of 368 base pairs (bp), encompassing nucleotide positions from 16032 to 16399 . The sequences are available upon request from the corresponding author.

The HVS-I hypervariable region was PCR amplified using $0.20 \mu \mathrm{M}$ L15971-H16414 primers [22] in a $20-\mu$ l reaction volume also containing $0.4 \mathrm{mM}$ dNTP mix, 1 unit GoTaq $^{\circledR}$ Flexi DNA Polymerase (Promega Corporation, Madison, Wisc., USA) and 10 ng DNA. PCR reactions were carried out in a T-Gradient Thermocycler (Whatman Biometra, Goettingen, Germany) with the following amplification profile: initial denaturation $95^{\circ} \mathrm{C}$ for $5 \mathrm{~min}, 40$ cycles of $95^{\circ} \mathrm{C}$ for $45 \mathrm{~s}, 69^{\circ} \mathrm{C}$ for $45 \mathrm{~s}, 72^{\circ} \mathrm{C}$ for $1 \mathrm{~min}$ and final extension at $72^{\circ} \mathrm{C}$ for $5 \mathrm{~min}$. Amplicons were visualized by electrophoresis on a $2 \%$ agarose gel stained with ethidium bromide and then purified using the ExoSAP-IT ${ }^{\circledR}$ for PCR clean-up (USB Corporation, Cleveland, Ohio, USA). Purified PCR products were used for sequencing reaction with the ABI Prism BigDye ${ }^{\circledR}$ Terminator v1.1 Cycle Sequencing Kit (Applied Biosystems, Foster City, Calif., USA) in $10 \mu \mathrm{l}$ reaction volumes with $1 \mu \mathrm{M}$ of the L15971 primer. The temperature sequencing profile involved 29 cycles with steps of $96^{\circ} \mathrm{C}$ for $10 \mathrm{~s}, 50^{\circ} \mathrm{C}$ for $15 \mathrm{~s}$ and $60^{\circ} \mathrm{C}$ for $4 \mathrm{~min}$, followed by holding at $4^{\circ} \mathrm{C}$. Sequencing reactions were repeated with the same conditions, but using the H16414 primer in order to sequence the HVS-I region in both directions. Sequenc- 
Table 1. Description of the studied Iranian ethnic groups

\begin{tabular}{lllllll}
\hline Ethnic group & Acronym & $\mathrm{N}$ & Location & Religion & Lf/Lfs/L & Subsistence \\
\hline Arab & $\mathrm{Ab}$ & 45 & Ahvaz & Islam & AA/S/Arabic & - \\
Armenian & $\mathrm{Ar}$ & 52 & Isfahan & Christian & IE/-/Armenian & - \\
Azeri & $\mathrm{Az}$ & 53 & Tabriz & Islam & A/T/Azerbaijani & farming \\
Baloch & $\mathrm{B}$ & 61 & Iranshahr & Islam & IE/II/Balochi & semi-nomadic \\
Gilak & $\mathrm{G}$ & 23 & Rasht & Islam & IE/II/Gilaki & farming \\
Jew & $\mathrm{J}$ & 56 & Shiraz & Judaism & IE/II/Dzhidi & - \\
Kurd & $\mathrm{K}$ & 55 & Saqqez & Islam & IE/II/Kurdish & nomadic \\
Lur & $\mathrm{L}$ & 30 & Khoramabad & Islam & IE/II/Southern Luri & nomadic \\
Lur & $\mathrm{L}$ & 29 & Yasouj & Islam & IE/II/Northern Luri & nomadic \\
Mazandarani & $\mathrm{M}$ & 51 & Sari & Islam & IE/II/Mazandrani & farming \\
Pars & $\mathrm{P}$ & 58 & Shiraz & Islam & IE/II/Parsi & - \\
Qashqaee & $\mathrm{Qa}$ & 46 & Fars province & Islam & A/T/Qashqa'i & nomadic \\
Qeshm & $\mathrm{Qe}$ & 55 & Qeshm Island & Islam & AA/S/Arabic & varying \\
Turkmen & $\mathrm{T}$ & 55 & Gonbad & Islam & A/T/Turkmen & nomadic \\
Zoroastrian & $\mathrm{Z}$ & 49 & Yazd & Zoroastrian & IE & - \\
\hline
\end{tabular}

$\mathrm{N}$ = Sample size; $\mathrm{Lf}=$ language family; $\mathrm{Lfs}=$ language family sublevel; $\mathrm{L}=$ language; $\mathrm{AA}=$ Afro-Asiatic; $\mathrm{S}=\mathrm{Semitic} ; \mathrm{A}=\mathrm{Altaic}$; $\mathrm{T}=$ Turkic; IE = Indo-European; II = Indo-Iranian.

ing products were precipitated using ethanol, dried, and finally re-suspended in $30 \mu \mathrm{l}$ deionized formamide loading solution to be analyzed on an automatic sequencer ABI Prism ${ }^{\mathrm{TM}} 3730 \mathrm{Ge}-$ netic Analyzer (Applied Biosystems, Foster City, Calif., USA). The CHROMAS 2.33 software was used to read the obtained electropherograms, whereas DNA_Aligment 1.3.1.1 was used to align HVS-I sequences to the revised Cambridge reference sequence (rCRS) and detect polymorphic sites. mtDNA haplogroups were determined on the basis of diagnostic sites in the D-loop region following mtDNA tree Build 10 (http://www.phylotree.org/) and confirmed by a hierarchical analysis of the coding region by testing a total of 21 restriction fragment length polymorphisms (RFLPs) (online suppl. table 1, for all online supplementary material see www.karger.com/doi/10.1159/000330166).

\section{Statistical Analyses}

Estimates of basic descriptive statistics for each of the examined populations, such as haplotype diversity $(\mathrm{H})$ and the mean number of pairwise differences (MPD), as well as pairwise $F_{S T}$ genetic distances among all groups were computed using the Arlequin package [23] version 3.5.1.2. A $F_{S T}$ genetic distance matrix [24] was obtained and used for a graphical representation by means of a non-metric multidimensional scaling (NM-MDS) [25], as well as for testing the presence of potential correlations between the genetic and geographic distances of the surveyed samples by means of a Mantel test [26]. Pairwise population geographic distances were computed according to the sampling locations reported in table 1 and in online supplementary table 2 and using the spaa library implemented in the $\mathrm{R}$ package 2.12.0 (http://www.r-project.org/). An apportionment of the genetic variance among linguistically- and geographically-based groups of populations was investigated with a locus-by-locus analysis of the molecular variance (AMOVA) [27]. A series of spatial analysis of the molecular variance (SAMOVA) [28] was also per-

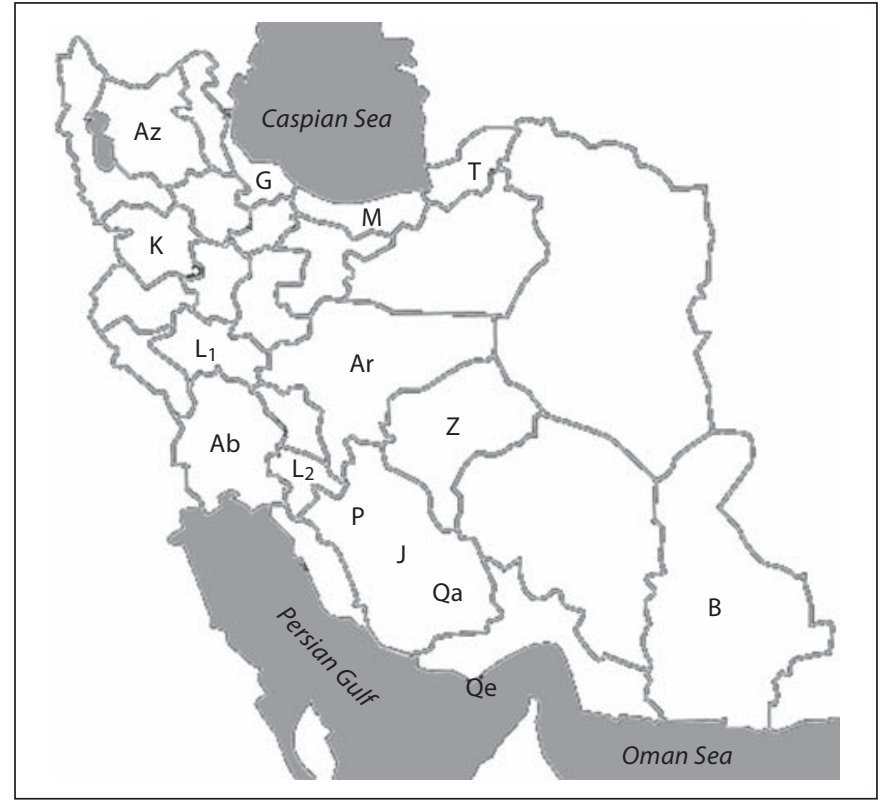

Fig. 1. Geographic localization of the studied Iranian ethnic groups (see table 1 for the acronyms of each ethnic group).

formed, each testing a different number of unknown population groups $(2 \leq \mathrm{k} \leq 9)$, in order to identify clusters that are geographically homogeneous and maximally differentiated from each other, thus enabling the detection of potential genetic barriers among the different Iranian samples. A spatial principal component analysis (sPCA) [29] was carried out using the $\mathrm{R}$ 
Table 2. Summary statistics and Tajima's D test for the mtDNA HVS-I region in the studied Iranian ethnic groups

\begin{tabular}{|c|c|c|c|c|c|c|}
\hline $\begin{array}{l}\text { Ethnic } \\
\text { group }\end{array}$ & $\begin{array}{l}\text { Sample size } \\
\mathrm{n}\end{array}$ & $\begin{array}{l}\text { Polymorphic } \\
\text { sites, } \mathrm{n}\end{array}$ & $\begin{array}{l}\text { Haplotypes } \\
\mathrm{n}\end{array}$ & $\mathrm{H}$ & MPD & Tajima's D (p value)* \\
\hline $\mathrm{Ab}$ & 45 & 66 & 42 & $0.995 \pm 0.006$ & 6.359 & $-2.04077(0.001)$ \\
\hline $\mathrm{Ar}$ & 52 & 73 & 45 & $0.995 \pm 0.005$ & 6.357 & $-2.12151(0.002)$ \\
\hline $\mathrm{Az}$ & 53 & 74 & 50 & $0.998 \pm 0.004$ & 6.922 & $-1.98696(0.009)$ \\
\hline B & 61 & 60 & 41 & $0.952 \pm 0.020$ & 4.849 & $-2.05797(0.006)$ \\
\hline G & 23 & 47 & 21 & $0.992 \pm 0.015$ & 6.755 & $-1.79160(0.019)$ \\
\hline $\mathrm{J}$ & 56 & 40 & 23 & $0.941 \pm 0.015$ & 6.696 & $-0.70590(0.283)$ \\
\hline K & 55 & 63 & 47 & $0.992 \pm 0.006$ & 6.232 & $-1.87240(0.006)$ \\
\hline $\mathrm{L}_{1}$ & 30 & 56 & 26 & $0.977 \pm 0.021$ & 6.917 & $-1.97678(0.016)$ \\
\hline $\mathrm{L}_{2}$ & 29 & 43 & 21 & $0.963 \pm 0.023$ & 6.318 & $-1.51419(0.050)$ \\
\hline M & 51 & 59 & 36 & $0.980 \pm 0.009$ & 5.602 & $-1.95557(0.006)$ \\
\hline $\mathrm{P}$ & 58 & 84 & 53 & $0.995 \pm 0.005$ & 6.517 & $-2.21796(0.000)$ \\
\hline Qa & 46 & 50 & 30 & $0.948 \pm 0.024$ & 5.331 & $-1.82758(0.019)$ \\
\hline $\mathrm{Qe}$ & 55 & 66 & 37 & $0.970 \pm 0.013$ & 6.633 & $-1.85085(0.010)$ \\
\hline $\mathrm{T}$ & 55 & 69 & 44 & $0.990 \pm 0.006$ & 6.782 & $-1.91648(0.010)$ \\
\hline $\mathrm{Z}$ & 49 & 42 & 19 & $0.910 \pm 0.023$ & 7.043 & $-0.84036(0.209)$ \\
\hline
\end{tabular}

adegenet library to explore whether geographical features structure the observed Iranian mtDNA variability, according to the identification of potential positive/negative spatial autocorrelations in the examined dataset. A correspondence analysis (CA) focused on the frequencies of the main mtDNA haplogroups in each Iranian sample was computed by means of the R $c a$ library and plotted using a 'symmetric' scaling option, with the aim of identifying which lineages mainly contributed to the ethnic groups' differentiation. According to this plotting procedure, both the row (haplogroups) and column (populations) points are scaled in order to have inertias equal to the principal inertia along the principal axes, thus being displayed in principal coordinates. Potential departures from a null hypothesis of mutation-drift equilibrium and constant population size [i.e. from the $\theta$ parameter equation calculated according to the mean pairwise difference $(\pi)$ and the number of segregating sites (S)] were tested by computing the Tajima's D test for selective neutrality using the Arlequin package [30]. As a matter of fact, when selective events can be confidently excluded, as is the case of HVS-I variants, significant $\mathrm{D}$ values suggesting an excess of segregating sites (lowfrequency variants) can be better explained as a consequence of population expansions. Deviations from a model of sudden expansion (i.e. the passage from $\mathrm{N}_{0}$ to $\mathrm{N}_{1}$ population size $\tau$ generations ago) were tested using the Arlequin package and calculating the parameters $\left(\tau, \theta_{0}, \theta_{1}\right)$ according to Schneider and Excoffier [31] and the raggedness index ( $r$ ) defined by Harpending [32]. Significance of the difference between observed and expected distributions was assessed by a non-linear least-square approach. Evolutionary relationships among the mtDNA HVS-I haplotypes were visualized by means of the median joining network algorithm [33] implemented in the Network 4.5.1.6 software (http:// www.fluxus-engineering.com).

\section{Results}

\section{Sequence Variability and Demographic Inferences}

Summary statistics of mtDNA HVS-I variability are reported in table 2. Relatively low $\mathrm{H}$ was calculated for Qashqaees $(\mathrm{H}=0.948)$, Lurs from Yasouj $(\mathrm{H}=0.963)$, Balochis $(H=0.952)$, Jews $(H=0.941)$ and Zoroastrians $(\mathrm{H}=0.910)$. Another estimator of sequence diversity, the MPD, confirmed a marked reduction of variability only in the Qashqaee $(\mathrm{MPD}=5.331)$ and Baloch $(\mathrm{MPD}=$ 4.849) samples. The coexistence of low $\mathrm{H}$ and high MPD values observed in Zoroastrians, Jews and southern Lurs is best explained by deep haplotype genealogies evolved in small populations of constant size.

More accurate demographic inferences can be drawn by analyzing the shape of the distribution of pairwise differences, with populations having passed through a recent expansion, or a spatial expansion with intensive gene flow, showing smooth unimodal curves and populations at demographic equilibrium showing ragged multimodal curves. Mismatch curves of HVS-I haplotypes were smooth and unimodal in almost all the examined Iranian groups, with the exception of Zoroastrians $(r=0.034$; $\mathrm{p}<0.001)$ and Jews $(\mathrm{r}=0.080 ; \mathrm{p}<0.001)$ (fig. 2, 3). Interestingly, the latter also showed a high frequency of exactly matching haplotypes (i.e. no mutational differences between sequences), most likely due to considerable levels 


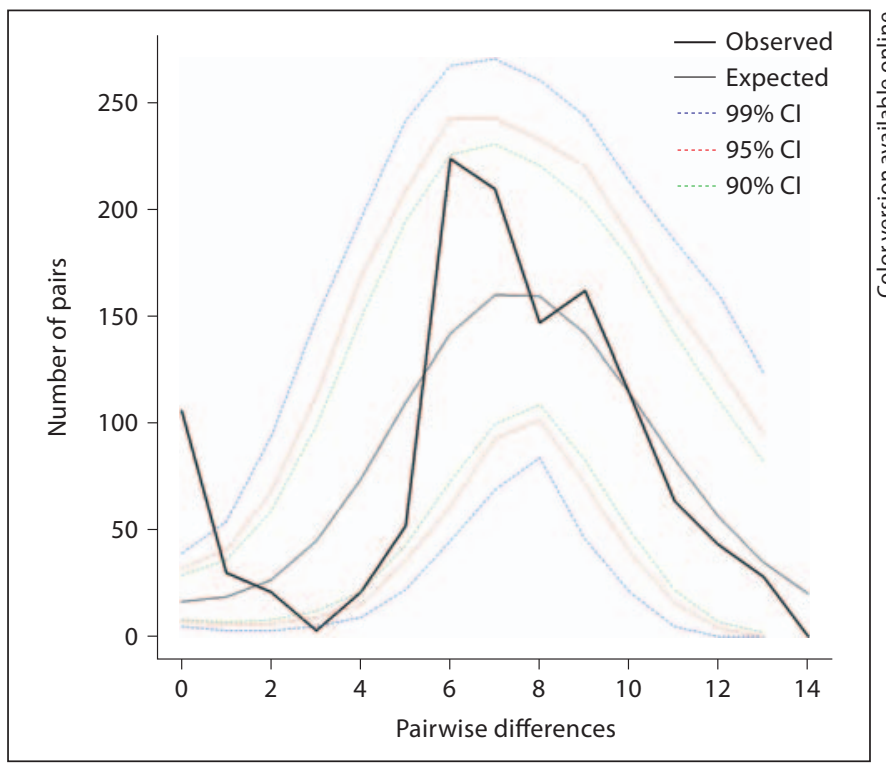

Fig. 2. Multimodal mismatch distribution for the Zoroastrian sample.

of female endogamy. Tajima's D estimates further confirmed the described pattern, being strongly negative and significantly different from zero for the total sample and for almost all single Iranian ethnic groups, reflecting an excess of singletons and low-frequency variants in the surveyed mtDNA pools as the result of recent demographic expansions, but again with the exception of Zoroastrians and Jews (table 2).

\section{Population Structure}

Pairwise $F_{S T}$ genetic distances computed among the 15 examined Iranian samples and 70 reference samples of Middle Eastern, Caucasian, European, Central Asian, Arabian/North-African, Indian and Pakistani ancestry (online suppl. table 2) were graphically represented by means of a NM-MDS (fig. 4a). Stress values of the NMMDS scaled at two and three dimensions $(0.1558, \mathrm{p}<$ $0.01 ; 0.1165, \mathrm{p}<0.01)$ were consistent with a non-random distribution of populations in the obtained plots. The majority of Iranian groups clustered near the origin of the axes, in an intermediate position between Middle Eastern, Caucasian and European populations on one side, and Central Asian and Arabian/North-African populations on the other side. Again, Zoroastrians and Jews appeared as outliers within Iranian mtDNA variability, as well as Lurs from Yasouj, who plotted closer to Caucasians, and Balochis, who showed high affinity with the

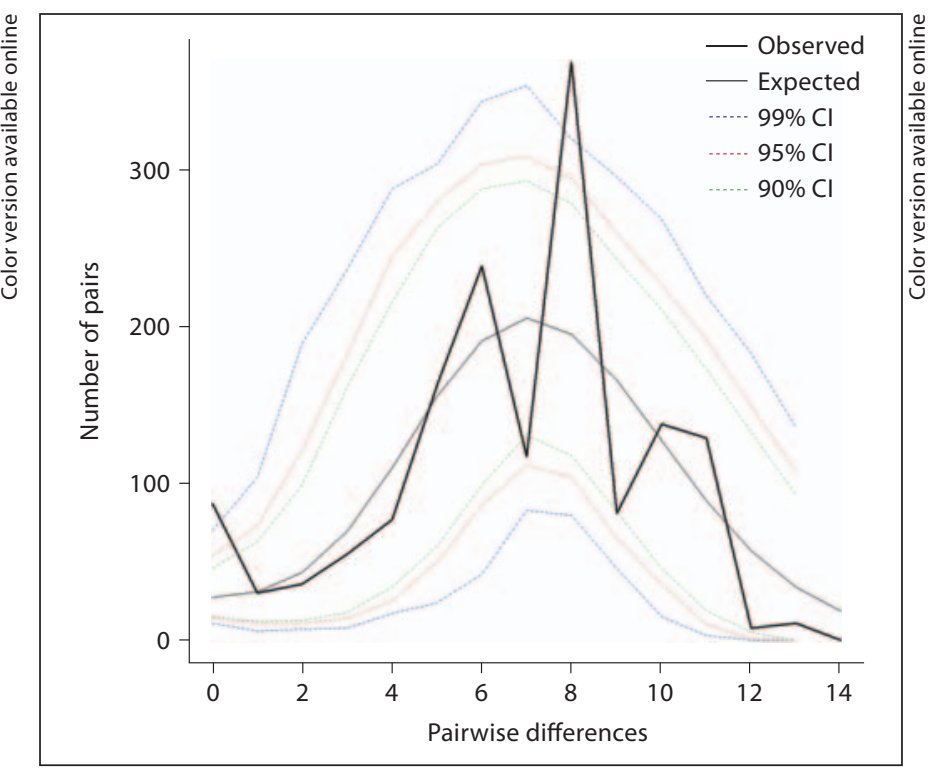

Fig. 3. Multimodal mismatch distribution for the Iranian Jew sample.

Balochis from Pakistan. Detailed reciprocal positions of the other Iranian groups are given in figure $4 \mathrm{~b}$.

The lack of a sharp geographical or ethno-linguistic structure for mtDNA HVS-I sequence diversity was statistically supported by different tests. According to AMOVA results (table 3), the majority of haplotype variation was indeed accounted for by within-population differences $(97.27 \%, \mathrm{p}<0.001)$ and, when population samples were subdivided according to either spoken language (Afro-Asiatic, Altaic and Indo-European language families) or geography (North-West and South-Central Iran), the among-groups component of variance ( $F_{C T}$ value) was always low and not significant. Moreover, when removing the outlier groups (Zoroastrians, Jews and Balochis) from the analyses, $F_{S T}, F_{S C}$ and $F_{C T}$ values, as well as the amonggroups and the among-populations-within-groups component of total variation, decreased for both the grouping criteria (data not shown). Highly significant correlations between genetic and geographic distances were found when the whole dataset of reference populations was included in the analysis $\left(\mathrm{r}=0.39, \mathrm{p}=9.9 \times 10^{-5}\right.$ for Pearson's correlation and $\mathrm{r}=0.49, \mathrm{p}=9.9 \times 10^{-5}$ for Spearman's correlation). On the contrary, very low and not significant values were observed when only the Iranian samples were considered $(r=0.09, p=0.31$ for Pearson's correlation and $\mathrm{r}=0.12, \mathrm{p}=0.23$ for Spearman's correlation). According to the sequential increase of population clusters obtained 
Fig. 4. a NM-MDS representation of genetic distances among the studied Iranian ethnic groups and 70 Middle Eastern, Caucasian, European, Central Asian, Arabian/North-African, Indian and Pakistani populations (stress 0.1558, $\mathrm{p}<0.01$ ). b NM-MDS representation of the genetic distances described above, zoomed on the core group of the examined Iranian populations.

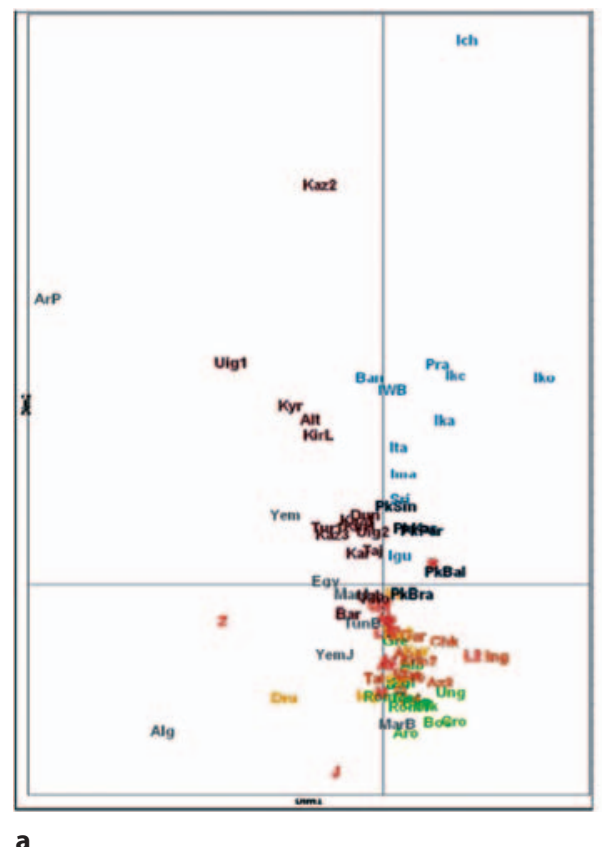

a

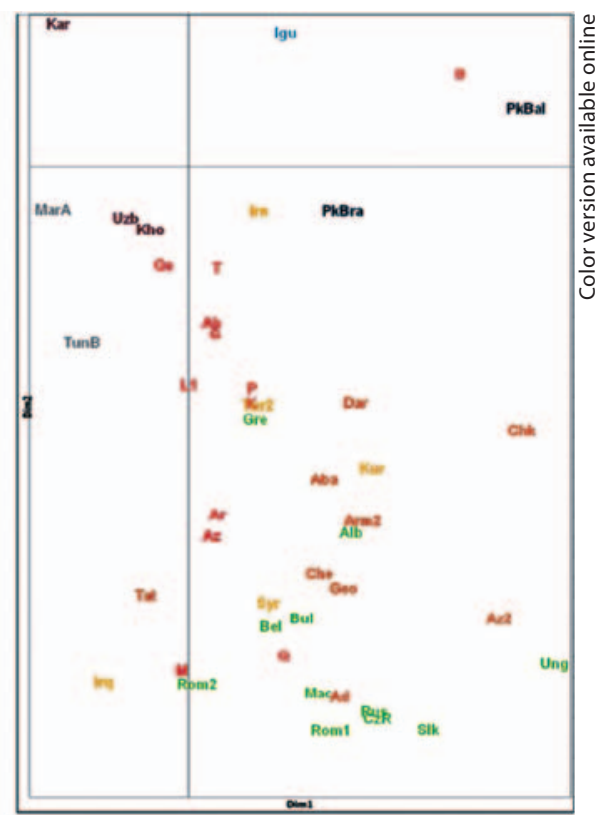

b

Table 3. AMOVA of the studied Iranian ethnic groups according to linguistic and geographic classification

\begin{tabular}{|c|c|c|c|c|c|c|}
\hline \multirow[t]{2}{*}{ Classifications } & \multicolumn{3}{|c|}{ Percentages of genetic variance } & \multicolumn{3}{|c|}{ Fixation indeces } \\
\hline & $\begin{array}{l}\text { among } \\
\text { pop./groups }\end{array}$ & $\begin{array}{l}\text { among pop. } \\
\text { within groups }\end{array}$ & $\begin{array}{l}\text { within } \\
\text { pop. }\end{array}$ & $F_{C T}$ & $F_{S C}$ & $F_{S T}$ \\
\hline No grouping & 2.73 & & 97.27 & & & $0.027^{*}$ \\
\hline Language family ${ }^{\mathrm{a}}$ & -0.27 & 2.89 & 97.38 & -0.0027 & $0.029^{*}$ & $0.026^{*}$ \\
\hline Geography ${ }^{b}$ & 0.09 & 2.68 & 97.22 & 0.001 & $0.027^{*}$ & $0.028^{*}$ \\
\hline
\end{tabular}

a Afro-Asiatic, Altaic, Indo-European. ${ }^{\mathrm{b}}$ North-West Iran, South-Central Iran. ${ }^{*} \mathrm{p}<0.001$.

by a series of SAMOVA analyses (table 4), maximization of the genetic differentiation between groups was achieved when three different population clusters were identified: two were represented by the Zoroastrian and the Jewish communities, whereas the third included all the remaining Iranian ethnic groups. Such clustering configuration indeed showed the greater among-groups percentage of variance $(4.26 \%)$, with a significant but low among-groups fixation index $\left(F_{C T}=0.043, \mathrm{p}=0.009\right)$, suggesting the presence of an appreciable genetic discontinuity among Zoroastrians, Jews and the bulk of Iranian samples. A spatial autocorrelation analysis was also performed by means of sPCA in order to further explore how far geographical features correlate with mtDNA variance. When the whole dataset of reference populations was included in the anal- ysis, a clear global structure (i.e. positive spatial autocorrelation indicating that mtDNA HVS-I sequences observed at neighboring populations tend to be similar) was found (Global test $=0.113, \mathrm{p}=1 \times 10^{-4}$; Local test $=0.023$, $\mathrm{p}=0.994)$. On the contrary, when sPCA was performed only on the Iranian samples, the strongest global eigenvalue and the strongest local eigenvalue ( $\lambda 1$ and $\lambda 14$; online suppl. fig. 1) exhibit respectively a not so high variance and a not so high Moran's I index, preventing the identification of significant positive or negative spatial autocorrelations (global test $=0.117, \mathrm{p}=0.581$; local test $=$ $0.149, \mathrm{p}=0.391$ ) and suggesting that the examined Iranian ethnic groups are not more genetically similar/dissimilar to their immediate neighbors than expected in a random spatial distribution. 


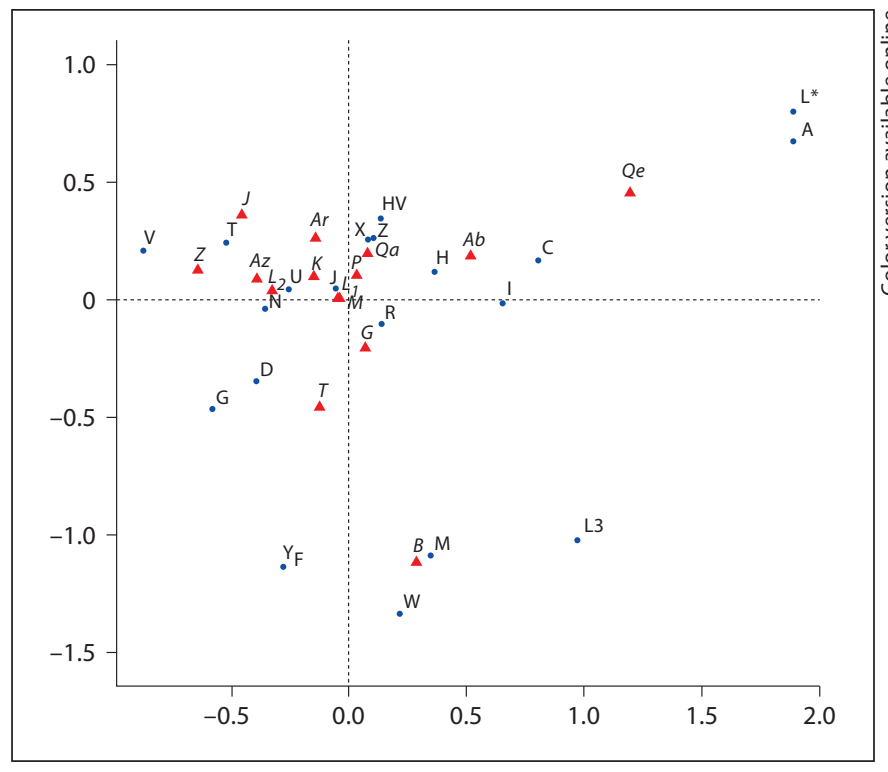

Fig. 5. CA showing the Iranian ethnic groups' distribution according to their haplogroup frequencies. Triangles indicate the Iranian ethnic groups (labels in italics), whereas circles indicate the haplogroups.

\section{Haplogroup-Specific Profiles}

A total of 71 main mitochondrial lineages (haplogroups) were identified in the whole Iranian sample (online suppl. table 3). Widespread West-Eurasian lineages such as $\mathrm{H}, \mathrm{HV}, \mathrm{I}, \mathrm{J}, \mathrm{K}, \mathrm{N}, \mathrm{T}, \mathrm{U}, \mathrm{V}$ and $\mathrm{W}$ accounted for the great majority of the surveyed mtDNAs (90.8\%), whereas typical East-Eurasian (A, C, D, F, G and Z), South-Asian (M) and Sub-Saharan African (L1, L2, L3) lineages were observed in a few ethnic groups. Within West-Eurasian lineages, $\mathrm{H}$ and $\mathrm{U}$ macro-haplogroups turned out to be by far the predominant lineages at equal rates (16.4\%). Haplogroup $\mathrm{H}$ was the most frequent clade in almost all groups, with the exception of Balochis, Jews, Lurs from Yasouj, and Zoroastrians, in whom it was even missing at all (online suppl. table 3). Curiously, haplogroup U7 reached 34.5\% in Lurs from Yasouj, but was completely missing in Armenians, Gilakis and people from Qeshm Island. CA performed using the frequencies of the main mtDNA haplogroups in each Iranian sample identified a first and a second dimension which explained respectively 26 and $21 \%$ of the overall variance of the haplogroups data matrix and failed to clearly separate most of the examined groups (fig. 5). As a matter of fact, the great majority of Iranian samples tend to cluster together due to a common mtDNA haplogroup background essentially made up of the West-Eurasian lineages mentioned
Table 4. SAMOVA of the studied Iranian ethnic groups

\begin{tabular}{|c|c|c|c|c|c|c|}
\hline \multirow[t]{2}{*}{ K } & \multicolumn{3}{|c|}{ Percentages of genetic variance } & \multicolumn{3}{|c|}{ Fixation indeces } \\
\hline & $\begin{array}{l}\text { among } \\
\text { pop./groups }\end{array}$ & $\begin{array}{l}\text { among pop. } \\
\text { within groups }\end{array}$ & $\begin{array}{l}\text { within } \\
\text { pop. }\end{array}$ & $F_{C T}$ & $F_{S C}$ & $F_{S T}$ \\
\hline 2 & 4.13 & 3.13 & 93.75 & 0.041 & $0.022^{*}$ & $0.063^{*}$ \\
\hline 3 & 4.26 & 1.51 & 94.23 & $0.043^{*}$ & $0.016^{*}$ & $0.058^{*}$ \\
\hline 4 & 3.79 & 1.18 & 95.03 & 0.038 & $0.012^{*}$ & $0.049^{*}$ \\
\hline 5 & 3.86 & 0.68 & 95.46 & $0.039^{*}$ & $0.007^{*}$ & $0.045^{*}$ \\
\hline 6 & 3.8 & 0.50 & 95.70 & $0.038^{*}$ & $0.005^{*}$ & $0.043^{*}$ \\
\hline 7 & 3.5 & 0.49 & 96.00 & $0.035^{*}$ & $0.005^{*}$ & $0.039^{*}$ \\
\hline 8 & 3.26 & 0.38 & 96.37 & 0.033 & $0.004^{*}$ & $0.036^{*}$ \\
\hline 9 & 3.15 & -0.07 & 96.92 & $0.031^{*}$ & $-0.001^{*}$ & $0.031^{*}$ \\
\hline
\end{tabular}

$\mathrm{K}$ = Population groups: $2=\mathrm{Z}$, all the remaining Iranian samples; $3=Z$, J, all the remaining Iranian samples; $4=Z$, J, Qe, all the remaining Iranian samples; $5=\mathrm{Z}, \mathrm{J}, \mathrm{Qe}, \mathrm{B}$, all the remaining Iranian samples; $6=\mathrm{Z}, \mathrm{J}, \mathrm{Qe}, \mathrm{B}, \mathrm{L}_{2}$, all the remaining Iranian samples; $7=Z$, J, Qe, $B, L_{2}, L_{1}$, all the remaining Iranian samples; $8=\mathrm{Z}, \mathrm{J}, \mathrm{Qe}, \mathrm{B}, \mathrm{L}_{2}, \mathrm{~L}_{1}, \mathrm{~T}$, all the remaining Iranian samples; $9=\mathrm{Z}$, J, Qe, B, $\mathrm{L}_{2}, \mathrm{~T}, \mathrm{G}+\mathrm{L}_{1}+\mathrm{M}+\mathrm{Ab}+\mathrm{Az}+\mathrm{P}+\mathrm{K}, \mathrm{Ar}+\mathrm{Qa}$.

${ }^{*} \mathrm{p}<0.001$.

above. East-Eurasian clades instead summed up to $2.8 \%$ of the examined mtDNAs, but cumulated in Turkmens (10.9\%) and people from Qeshm Island (10.3\%). M and its sub-clades accounted for $2.5 \%$ of lineages, with the highest frequency in Balochis (11.3\%), while Sub-Saharan African L clades represented $2.2 \%$ of the observed haplogroups, with frequency peaks in people from Qeshm Island (12.7\%) and Arabs (11.1\%). According to this, haplogroup A and the Sub-Saharan African $\mathrm{L}^{*}$ lineages strongly contributed to separate people from Qeshm Island along the first dimension of the CA plot, whereas the outlier position of Balochis along the second dimension is mainly due to their high frequencies of haplogroup W and of South-Asian M clades (fig. 5). Outstanding percentages were indeed observed in Balochis (24.2\%) and Gilakis (13.0\%) for the W lineage. R0 and its sub-clades were also well-represented lineages in the surveyed samples, showing a cumulative frequency of $14.0 \%$. This was mainly due to haplogroup HV, frequent in Mazandaranis, Jews, people from Qeshm Island and in Lurs (all above $10 \%)$. Finally, Zoroastrians showed an uncommon concentration of R0 (17.6\%) and T (35.3\%) lineages; Jews of $\mathrm{T}(32.7 \%)$ and $\mathrm{J} 2 \mathrm{~b}(12.73 \%)$ clades. Both these groups indeed tended to diverge along the first dimension of the CA plot from the main cluster of Iranian samples according to unexpected high concentrations of $\mathrm{T}$ lineages. 
Fig. 6. Median joining networks constructed for mtDNA HVS-I sequences from the examined Iranian samples (red), grouped according to U7 (left) and W (right) haplogroups and including sequence data from 70 European (green), Arabian/North-African (gray), Middle Eastern (orange), Indian (purple), Pakistani (blue), Chinese (yellow) and Ethiopian (fuchsia) populations. Colors refer to the online version.

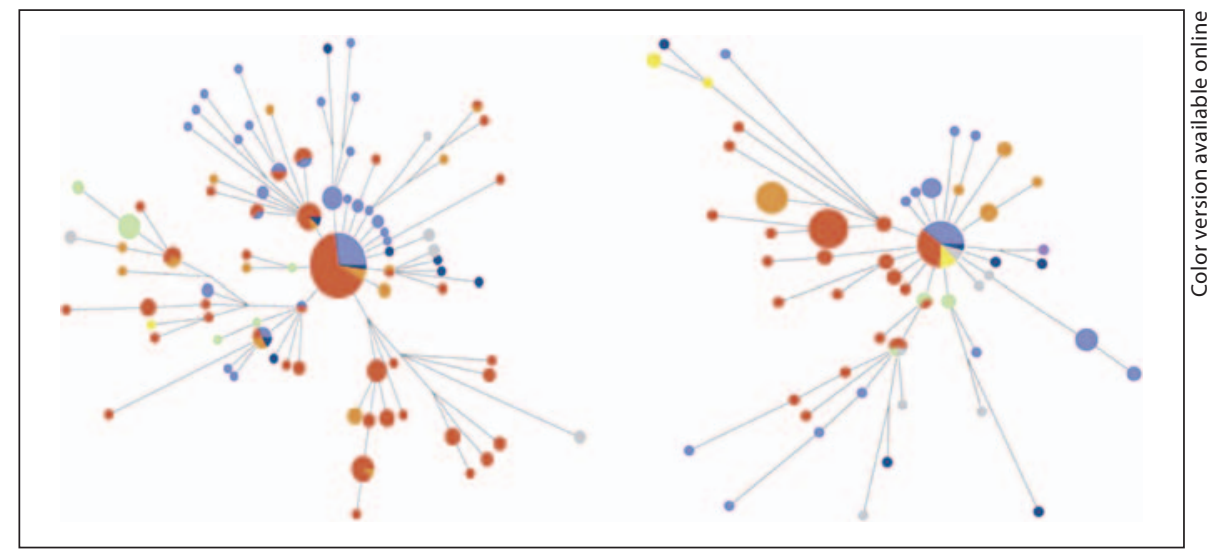

Moreover, although the East-Eurasian haplogroups G and D occurred at small frequencies, they actually had an influence on the distribution of the Turkmen sample in dimensional space, producing a sufficiently pronounced separation of this group along the second dimension of the CA plot (fig. 5).

\section{Phylogenetic Analysis of $U 7$ and $W$ Lineages}

Evolutionary relationships among the Iranian HVS-I haplotypes belonging to the U7 and $\mathrm{W}$ lineages are visualized in figure 6. Star-like structures were clearly detectable in the two median joining networks, with core haplotypes (U7: 16309G, 16318T; W: 129A, 223T) being shared among Iranians, Eastern and Western Eurasian populations. A high level of haplotype sharing between the Iranian and the Indo-Pakistani mtDNA pool was observed at U7 sequences, while higher affinities to Europeans and AfroAsiatic-speaking groups were inferred for W haplotypes.

\section{Comparative Analysis of Modern and Ancient HVS-I Haplotypes}

The occurrence of observed Iranian HVS-I haplotypes in extinct populations ordered according to a decreasing time scale is reported in table 5. Eleven haplotypes have been found in fifteen skeletal remains dated from the Early Neolithic to the 5th century AD. The rCRS [34], currently associated to $\mathrm{H}$ mitochondria was completely absent in Azeris, as well as in the two examined religious minorities (Zoroastrians and Jews), whereas exact matches between present-day Iranian and Upper Paleolithic European U4 and U5 haplotypes were observed. Moreover, a more direct association can be also inferred between Iranian ethnic groups with an ancient nomadic lifestyle and SouthSiberian tribes of the 'Kourgan culture' for T1 lineages.

\section{Discussion}

That the Iranian plateau acted as a natural hub for the expansions of human genes and cultures is widely accepted. The overlapping of prehistoric and more recent demographic events interacting at different time scales with geographical and cultural barriers has yielded a patchwork of anthropological types within this narrow area that genetic studies are nowadays trying to detail [12, 3537]. In this work, a comprehensive evaluation of this ethnic mosaic is given by depicting a fine-grained picture of the Iranian mitochondrial landscape.

mtDNA diversity encompassing most of the examined Iranian ethnic groups at both HVS-I and coding sequences lies within the range previously observed in populations speaking Indo-European or Semitic languages $[11,19,20,38-40]$. Moreover, the bulk of the Iranian mtDNA variability roughly occupies an intermediate position between Western and Central Asian populations, with a negligible internal structure. According to the insignificant correlation between genetic and geographic distances and the complete absence of spatial autocorrelations observed for the whole Iranian sample, it seems that a random mtDNA differentiation pattern with respect to geography can be invoked, suggesting that geographical factors did not actually represent insurmountable barriers to matrilineal gene flow among most of the surveyed groups. The same statement holds true also for cultural/linguistic differences, as showed by AMOVA results, and deviations from this rule are mainly due to recent limitations to exogamous marriages for members of religious minorities. As a matter of fact, SAMOVA identified a broad genetic homogeneity for almost all the examined Iranian samples 
Table 5. Exact matching between Iranian HVS-I haplotypes in the samples under study and ancient DNA sequences

\begin{tabular}{|c|c|c|c|c|c|c|}
\hline Place & Culture & Age & $\begin{array}{l}\text { Haplo- } \\
\text { group }\end{array}$ & HVS-I haplotype & $\begin{array}{l}\text { Haplotype matches } \\
\text { with Iranian samples }\end{array}$ & Reference $^{\mathrm{b}}$ \\
\hline Lithuania & Khunda & $6,350 \mathrm{BC}$ & U4 & $356 \mathrm{C}$ & $1 \mathrm{Ar} 1 \mathrm{~T}$ & Bramanti et al., 2009 \\
\hline Italy & Alpine & $4,240-3,930 \mathrm{BC}$ & $\mathrm{H}$ & rCRS & all except Az J Z & De Benedetto et al., 2000 \\
\hline Poland & Zedmar & $3,650 \mathrm{BC}$ & U5b1 & 189C 270T & $1 \mathrm{Ar}$ & Bramanti et al., 2009 \\
\hline Sweden & Funnel Beaker & $3,500-2,500 \mathrm{BC}$ & $\mathrm{H}$ & rCRS & all except Az J Z & Malmström et al., 2009 \\
\hline Germany & Funnel Beaker & $3,200-3,100 \mathrm{BC}$ & U5 & $270 \mathrm{~T}$ & $1 \mathrm{~B}$ & Bramanti et al., 2009 \\
\hline Syria & Sumerian & $2,900-2,700 \mathrm{BC}$ & U4 & $356 \mathrm{C}$ & $1 \mathrm{Ar} 1 \mathrm{~T}$ & Fernandez et al., 2005 \\
\hline Sweden & Pitted Ware & $2,800-2,000 \mathrm{BC}$ & U5 & $270 \mathrm{~T}$ & $1 \mathrm{~B}$ & Malmström et al., 2009 \\
\hline Russia & Kourgan & $1,800-1,400 \mathrm{BC}$ & $\mathrm{T} 1$ & 126C 163G 186T 189C 294T & $\begin{array}{l}\text { 1Ar 2Az 2K 2M } \\
1 \mathrm{Q} 2 \mathrm{P} 4 \mathrm{~T} 1 \mathrm{Z}\end{array}$ & Keyser et al., 2009 \\
\hline Kazakhstan & Kourgan & $1,400-1,000 \mathrm{BC}$ & $\mathrm{H}$ & rCRS & all except Az J Z & Lalueza-Fox et al., 2004 \\
\hline Kazakhstan & Kourgan & $1,400-1,000 \mathrm{BC}$ & $\mathrm{T} 1$ & 93C 126C 163G 186T 189C 294T & $3 Z$ & Lalueza-Fox et al., 2004 \\
\hline Kazakhstan & Kourgan & $700-600 \mathrm{BC}$ & $\mathrm{W}$ & $223 \mathrm{~T} 292 \mathrm{~T}$ & 1B 1G 1K 2M 1Q 1T & Lalueza-Fox et al., 2004 \\
\hline Kazakhstan & Kourgan & $700-400 \mathrm{BC}$ & $\mathrm{T} 2$ & 126C 294T 296T & $2 \mathrm{Az} 2 \mathrm{P}$ & Lalueza-Fox et al., 2004 \\
\hline Kazakhstan & Kourgan & $700-200 \mathrm{BC}$ & $A^{*}$ & 223T 290T 319A 362C & $1 \mathrm{~T}$ & Lalueza-Fox et al., 2004 \\
\hline Russia & Tachtik & $100-400 \mathrm{AD}$ & $\mathrm{HV}$ & $72 \mathrm{C} 311 \mathrm{C}$ & $1 \mathrm{P}$ & Keyser et al., 2009 \\
\hline Kazakhstan & Kourgan & $200-500 \mathrm{AD}$ & U1a & 183C 189C 249C & $3 \mathrm{~J}$ & Lalueza-Fox et al., 2004 \\
\hline
\end{tabular}

${ }^{a}$ Populations' acronyms as reported in table $1 .{ }^{b}$ Reported in the online supplementary references file.

in contrast to a more pronounced genetic discontinuity between them and the Zoroastrian and Jewish communities, suggesting these latter groups are plausibly separated from the bulk of Iranian mtDNA variability by effective barriers. According to this overall view, population inferences sustained by mitochondrial evidence somewhat clash with the observed geographic apportionment of $\mathrm{Y}$ chromosome variability in North and South Iran [13], justified by natural barriers to gene flow, such as the Zagros mountain range, as well as the Lut and Kavir deserts.

Reduced levels of mtDNA variability at binary and hypervariable markers are instead found for a few groups, such as Zoroastrians, Jews, Qashqaees, Lurs from Yasouj and Balochis who showed haplotype diversity values which fell outside the lower bound of previously investigated populations speaking Indo-European and Semitic languages from the South Caucasus, Middle East, West Asia and North Africa [11, 19, 20, 38-40]. Moreover, the Baloch sample coupled low HVS-I diversity with a heterogeneous haplogroup composition. In particular, Zoroastrians, Jews and Lurs from Yasouj stand out as perfect genetic outliers also in the genetic hyperspace based on haplogroup diversity, moving away from the central core of Iranian ancestry in different directions.
In contrast, the slightly shifted position of Balochis, Qashqaees and Mazandaranis seems to be consistent with historic clues about their ancestry. Baloch people from the South-Eastern corner of the Iranian plateau and Pakistani from Balochistan indeed claim a strong identity. Their cultural traditions, including a language belonging to the same branch of the Indo-European language family, are generally traced back to ancient Medes and Persian tribes. However, mitochondrial affinities with populations from the Indus valley are reflected in the high frequency of the macro-haplogroup $M[41,42]$ (fig. 5) and in the shared founder haplotype of lineage W (fig. 6), whose geographic distribution and coalescence time largely overlap with those of haplogroup U7 [17, 43] and which reached an outstanding percentage of $24.2 \%$ in Balochis. These evidences, together with the recent discovery of an early center of farming and domestication at Mehergarh pre-dating the Mesopotamia civilization (7,000 to 2,000 BC), strongly suggest that many of the present Baloch mtDNA lineages could be direct descendants of Neolithic females. According to this, their cultural isolation, probably exacerbated by geographical features such as the mountainous district in which they live, the surrounding Lut and Kavir deserts, as well as the Zagros Mountains, may have for a long time limited North- 
ern and Western Iranian districts' gene flow, making their mtDNA pool a plausible relic of autochthonous Iranian tribes inhabiting the area before the arrival of the Aryans. As regards Qashqaees, they still preserve a nomadic lifestyle and a Turkic language so that their position on the MDS plot suggests a legacy with tribes of herders from an undefined Anatolian Caucasian area. Caspian people, such as Mazandaranis and Gilakis, are instead supposed to have the same South-Caucasian origin. However, on the basis of their position on the MDS graph, only Mazandaranis seem to have largely preserved the ancestral Caucasian profile and, in contrast to what has previously been recognized [18], with scarce introgression of mtDNA types from local Iranians.

Contrary to what is observed for Balochis, Qashqaees and Mazandaranis, the high genetic distance between Lur groups sounds somewhat unexpected. A mitochondrial support to the historical hypothesis of a common legacy for Lurs and Kurds is in fact only given by the mtDNA profile of Lurs from North Luristan (Khoramabad), which occupied a contiguous position with the Kurd sample on the MDS graph (fig. 4). Mitochondria of Lurs from Yasouj tell us another story. This group appears to be distantly related to neighboring populations (Pars, Arab and Qashqaee people). Their origins can be more likely traced back either to the Kassites, the native people of Luristan, or Elamites, who occupied the territory before the arrival of the Aryans. The Kassites were a body of Zagros tribes that, after being defeated by the Elamites around 1,200 BC, retreated back to the Luristan highlands. Even after the annexation to the Persian Empire, these tribes would have maintained a high degree of isolation that limited the introgression of Indo-European lineages in their mitochondrial pool. The strikingly high frequency of the ancient autochthonous U7 lineage (34.48\%), the occurrence of rare haplogroups (K1a9 [44] and M1 [45]), and the narrower spectrum of lineages that characterize the reduced mtDNA variability of Lurs from Yasouj support this hypothesis.

A different pattern of isolation is observable for the other two genetic outliers, the Zoroastrians and the Jews. Although Iranian people are mostly Muslims, Zoroastrianism and Judaism still represent two of the ethno-religious minorities present on the Iranian territory, accounting for approximately $0.02-0.05 \%$ of the whole population. Zoroastrianism originated between the 9th and 6th centuries BC and was introduced as the official religion by Sassanid during the last pre-Islamic Persian Empire [46], whereas the Iranian Jewish community assumedly settled in Iran in the 6th century BC. Neverthe- less, a signature of isolation for these groups can be clearly identified in the peak of matching haplotypes far above the level expected under a sudden expansion model and absolutely missing in the curves calculated from the other examined mitochondrial pools. Most probably it is the consequence of the onset of limitations to exogamous marriages as regards followers of different religions which occurred after the spread of Islam. Long-term isolation for Zoroastrians and Jews is detectable also from other estimators such as a ragged multimodal mismatch distribution (fig. 2,3) and the scarceness of segregating sites (Tajima's D values) (table 2).

In accordance with the above considerations are the results from the comparative analysis of modern and ancient HVS-I haplotypes (table 5). Although rCRS occurs in Western Eurasian populations since so much time that it is useless to discern among demographic events, its absence in Zoroastrians and Jews suggests that it should have undergone strong genetic drift and/or founder effects. More generally, the exact matches between presentday Iranian and Upper Paleolithic European U4 and U5 haplotypes can be explained by the retention of sequences belonging to early phases of the colonization of Western Eurasia. Alternatively, they could come from more recent prehistoric migrations of nomadic people bearing Eurasian sequences into Central Asia and the Far East, and their subsequent downwards movement to Iran at the time of the Indo-European diffusion (1,300 BC). Such hypothesis relies on the data from the Yuansha site mummies (Xinjiang Province, North-Western China) which date back 2,135 years [47], showing genetic (mtDNA H lineages) and morphological traits (long noses, blonde hair) of the European type, as well as on the Tocharian language, an Indo-European relic in modern China. A more direct association can also be inferred between Iranian ethnic groups with an ancient nomadic lifestyle and South-Siberian tribes of the 'Kourgan culture' for T1 lineages. It has been supposed that Kurgan people spoke a Proto-Indo-Iranian or a Proto-Iranian language [48] and could have acted as vectors for the spread of the IndoEuropean language. A link between Iranian Jews and a Kourgan U1a haplotype dated to 100-400 AD raises the question regarding the extent of genetic admixture between Middle-Eastern and Central Asian components in this group.

Both demographic and ancient DNA evidence support the idea that Zoroastrian and Jewish genetic backgrounds (especially that of Zoroastrians) are the closest to the ancestral pre-Indo-Iranian gene pool. Having a close-up look at the Zoroastrian haplogroup repertoire, we can in- 
deed notice that more than one half of mtDNAs can be assigned to $\mathrm{T}^{*}$ and $\mathrm{R} 0$ lineages. The $\mathrm{T}$ haplogroup probably originated in the Middle East during the Paleolithic, but is now well-distributed also in Eastern and Northern Europe, as well as up to the Indus Valley and the Arabian Peninsula, and its younger sub-clades would have expanded in Europe and Central Asia during the Neolithic Transition. Haplogroup R0 instead occurs more frequently on the Arabian Peninsula [49] and in Pakistani Kalash [11] than in the rest of Eurasia. The unusual high percentages of $\mathrm{T}^{*}$ and $\mathrm{R} 0$ in the Zoroastrian sample may be interpreted as inheritance of the early groups of farmers involved in the eastwards expansion of agricultural techniques from the Fertile Crescent and Elam, whereas the contribution of Aryans to this genetic background can be confidently recognized in T1 lineages. As concerns Jews, they are characterized by an uncommonly high frequency of haplogroup J2b (12.73\%), which is mainly distributed around the Mediterranean Basin and generally less represented than other J sub-clades in the Middle East, by the ancient autochthonous lineage U7 (14.55\%) and by U1a lineages that were presumably inherited through the Kourgan people. That being so, it is clear that both Zoroastrian and Jewish communities have reached high degrees of isolation, endogamy and inbreeding in the last millennium and have strongly maintained this state up to the present. This allowed most of the mtDNAs of the autochthonous Iranian ancestors to survive foreign contributions to the Iranian gene pool in the recent past.

In conclusion, a discordant pattern of high ethno-linguistic and low mtDNA heterogeneity is observed in a large set of autochthonous groups from the Iranian plateau. Maternally transmitted genetic inheritance reflects the major role of the Iranian landmass as a crossroad for human migrations since prehistoric times, where the strong geographic and linguistic barriers were insufficient to generate a significant structure. Cultural, political, and, to a minor extent, geographical factors seem to have acted as an obstacle to maternal gene flow mostly in Balochis, Lurs from Yasouj, Qashqaees, Zoroastrians and Jews. In these few ethnic groups, deep rooting genealogies and endogamy might have preserved ancestral lineages that can be representative of Proto-Indo-Iranian or prehistoric mitochondrial profiles which survived more recent historical invasions of the Iranian territory.

\section{Acknowledgements}

We are grateful to all the participants who have taken part in this study. We also wish to express our gratitude to the anonymous reviewers who contributed with helpful suggestions to the improvement of the paper. This work was supported by the European Genetic Foundation (EGF), Shiraz University of Medical Sciences, RFO and 'Strategic Project 2006-2009' grants of the University of Bologna.

\section{References}

1 Luis JR, Rowold DJ, Regueiro M, Caeiro B, Cinnioğlu C, Roseman C, Underhill PA, Cavalli-Sforza LL, Herrera RJ: The Levant versus the Horn of Africa: evidence for bidirectional corridors of human migrations. Am J Hum Genet 2004;74:532-544.

2 Quintana-Murci L, Semino O, Bandelt HJ, Passarino G, McElreavey K, Santachiara-Benerecetti AS: Genetic evidence of an early exit of Homo sapiens sapiens from Africa through eastern Africa. Nat Genet 1999;23: 437-441.

3 Kivisild T, Bamshad MJ, Kaldma K, Metspalu M, Metspalu E, Reidla M, Laos S, Parik J, Watkins WS, Dixon ME, Papiha SS, Mastana SS, Mir MR, Ferak V, Villems R: Deep common ancestry of Indian and western-Eurasian mitochondrial DNA lineages. Curr Biol 1999;9:1331-1334.

-4 Macaulay V, Hill C, Achilli A, Rengo C, Clarke D, Meehan W, Blackburn J, Semino O, Scozzari R, Cruciani F, Taha A, Shaari NK, Raja JM, Ismail P, Zainuddin Z, Good- win W, Bulbeck D, Bandelt HJ, Oppenheimer S, Torroni A, Richards M: Single, rapid coastal settlement of Asia revealed by analysis of complete mitochondrial genomes. Science 2005;308:1034-1036.

5 Trinkaus E, Biglari F, Mashkour M, Monchot H, Reyss JL, Rougier H, Heydari S, Abdi $\mathrm{K}$ : Late Pleistocene human remains from Wezmeh Cave, western Iran. Am J Phys Anthropol 2008;135:371-378.

-6 Berillon G, Asgari Khaneghah A, Antoine P, Bahain JJ, Chevrier B, Zeitoun V, Aminzadeh N, Beheshti M, Chanzanagh HE, Nochadi S: Discovery of new open-air Paleolithic localities in Central Alborz, Northern Iran. J Hum Evol 2007;52:380-387.

7 Voigt Mary M, Dyson RH: The chronology of Iran ca. 8000 -2000 B.C.; in Ehrich RW (ed): Chronologies in Old World History, 3rd ed. Chicago, London, 1992, vol 2, pp 122-178.

8 Mortensen P: Seasonal camps and early villages in the Zagros; in Dimbleby G, Ucko P, Tringham R (eds): Man, Settlement and Ur- banism. London, Shenkman Pub. Co., 1972, pp 293-297.

9 Cavalli-Sforza LL: The spread of agriculture and nomadic pastoralism: Insights from genetics, linguistics and archaeology; in Harris DR (ed): The Origins and Spread of Agriculture and Pastoralism in Eurasia. Washington DC, Smithsonian Institution Press, 1996, pp 51-69.

10 Gumilyov LN: Ancient Turks. Moscow, 1967, Institute of Ethnology and Anthropology of the Academy of Sciences of USSR.

11 Quintana-Murci L, Chaix R, Wells RS, Behar DM, Sayar H, Scozzari R, Rengo C, Al-Zahery N, Semino O, Santachiara-Benerecetti AS, Coppa A, Ayub Q, Mohyuddin A, Tyler-Smith C, Qasim Mehdi S, Torroni A, McElreavey K: Where west meets east: the complex mtDNA landscape of the southwest and Central Asian corridor. Am J Hum Genet 2004;74:827-845.

12 Shepard EM, Herrera RJ: Iranian STR variation at the fringes of biogeographical demarcation. Forensic Sci Int 2006;158:140-148. 
13 Regueiro M, Cadenas AM, Gayden T, Underhill PA, Herrera RJ: Iran: tricontinental nexus for Y-chromosome driven migration. Hum Hered 2006;61:132-143.

$\checkmark 14$ Farjadian S, Ghaderi A: HLA class II genetic diversity in Arabs and Jews of Iran. Iran J Immunol 2007;4:85-93.

-15 Farjadian S, Ghaderi A: HLA class II similarities in Iranian Kurds and Azeris. Int J Immunogenet 2007;34:457-463.

-16 Farjadian S, Ota M, Inoko H, Ghaderi A: The genetic relationship among Iranian ethnic groups: an anthropological view based on HLA class II gene polymorphism. Mol Biol Rep 2009;36:1943-1950.

-17 Metspalu M, Kivisild T, Metspalu E, Parik J, Hudjashov G, Kaldma K, Serk P, Karmin M, Behar DM, Gilbert MT, Endicott P, Mastana S, Papiha SS, Skorecki K, Torroni A, Villems $\mathrm{R}$ : Most of the extant mtDNA boundaries in south and southwest Asia were likely shaped during the initial settlement of Eurasia by anatomically modern humans. BMC Genet 2004;5:26.

-18 Nasidze I, Quinque D, Rahmani M, Alemohamad SA, Stoneking M: Concomitant replacement of language and mtDNA in South Caspian populations of Iran. Curr Biol 2006; 16:668-673.

-19 Nasidze I, Quinque D, Rahmani M, Alemohamad SA, Stoneking M: Close genetic relationship between Semitic-speaking and Indo-European-speaking groups in Iran. Ann Hum Genet 2008;72:241-252.

-20 Nasidze I, Quinque D, Rahmani M, Alemohamad SA, Asadova P, Zhukova O, Stoneking $\mathrm{M}$ : mtDNA and Y-chromosome variation in the Talysh of Iran and Azerbaijan. Am J Phys Anthropol 2009;138:82-89.

-21 Miller SA, Dykes DD, Polesky HF: A simple salting out procedure for extracting DNA from human nucleated cells. Nucleic Acids Res 1988;16:1215

-22 Vigilant L, Pennington R, Harpending H, Kocher TD, Wilson AC: Mitochondrial DNA sequences in single hairs from a southern African population. Proc Natl Acad Sci USA 1989;86:9350-9354.

23 Excoffier L, Laval G, Schneider S: Arlequin ver. 3.0: An integrated software package for population genetics data analysis. Evol Bioinform Online 2005;1:47-50.

24 Slatkin M: A measure of population subdivision based on microsatellite allele frequencies. Genetics 1995;139:457-462.

25 Kruskal J: Nonmetric multidimensional scaling: a numerical method. Psychometrika 1964;29:28-42.
26 Mantel N: The detection of disease clustering and a generalized regression approach. Cancer Res 1967;27:209-220.

27 Excoffier L, Smouse PE, Quattro JM: Analysis of molecular variance inferred from metric distances among DNA haplotypes: application to human mitochondrial DNA restriction data. Genetics 1992;131:479-491.

28 Dupanloup I, Schneider S, Excoffier L: A simulated annealing approach to define the genetic structure of populations. Mol Ecol 2002;11:2571-2581.

29 Jombart T, Devillard S, Dufour AB, Pontier D: Revealing cryptic spatial patterns in genetic variability by a new multivariate method. Heredity 2008;101:92-103.

30 Tajima F: Statistical method for testing the neutral mutation hypothesis by DNA polymorphism. Genetics 1989;123:585-595.

-31 Schneider S, Excoffier L: Estimation of past demographic parameters from the distribution of pairwise differences when the mutation rates vary among sites: application to human mitochondrial DNA. Genetics 1999; 152:1079-1089.

32 Harpending HC: Signature of ancient population growth in a low-resolution mitochondrial DNA mismatch distribution. Hum Biol 1994;66:591-600.

33 Bandelt HJ, Forster P, Sykes BC, Richards MB: Mitochondrial portraits of human populations using median networks. Genetics 1995;141:743-753.

34 Andrews RM, Kubacka I, Chinnery PF, Lightowlers RN, Turnbull DM, Howell N: Reanalysis and revision of the Cambridge reference sequence for human mitochondrial DNA. Nat Genet 1999;23:147.

35 Farjadian S, Naruse T, Kawata H, Ghaderi A, Bahram S, Inoko $\mathrm{H}$ : Molecular analysis of HLA allele frequencies and haplotypes in Baloch of Iran compared with related populations of Pakistan. Tissue Antigens 2004;64: 581-587.

36 Farjadian S, Moqadam FA, Ghaderi A: HLA class II gene polymorphism in Parsees and Zoroastrians of Iran. Int J Immunogenet 2006;33:185-191.

-37 Amirzargar A, Sadeghi M, Khosravi F, Dianat S, Naroueynejad M, Nicknam MH, Hatmi N, Ansaripour B, Moradi B, Nikbin B: Th1 and Th2 cytokine gene polymorphisms in two indigenous ethnic groups in Iran. Int J Immunogenet 2006;33:429-437.

-38 Brakez Z, Bosch E, Izaabel H, Akhayat O, Comas D, Bertranpetit J, Calafell F: Human mitochondrial DNA sequence variation in the Moroccan population of the Souss area. Ann Hum Biol 2001;28:295-307.
39 Al-Zahery N, Semino O, Benuzzi G, Magri C, Passarino G, Torroni A, Santachiara-Benerecetti AS: Y-chromosome and mtDNA polymorphisms in Iraq, a crossroad of the early human dispersal and of post-Neolithic migrations. Mol Phylogenet Evol 2003;28: 458-472.

-40 Kivisild T, Reidla M, Metspalu E, Rosa A, Brehm A, Pennarun E, Parik J, Geberhiwot T, Usanga E, Villems R: Ethiopian mitochondrial DNA heritage: tracking gene flow across and around the gate of tears. Am J Hum Genet 2004;75:752-770.

41 Rajkumar R, Banerjee J, Gunturi HB, Trivedi R, Kashyap VK: Phylogeny and antiquity of $M$ macrohaplogroup inferred from complete mtDNA sequence of Indian specific lineages. BMC Evol Biol 2005;5:26.

-42 Thangaraj K, Chaubey G, Singh VK, Vanniarajan $A$, Thanseem $I$, Reddy AG, Singh L: In situ origin of deep rooting lineages of mitochondrial Macrohaplogroup ' $\mathrm{M}$ ' in India. BMC Genomics 2006;7:151.

43 Eaaswarkhanth M, Haque I, Ravesh Z, Romero IG, Meganathan PR, Dubey B, Khan FA, Chaubey G, Kivisild T, Tyler-Smith C, Singh L, Thangaraj K: Traces of sub-Saharan and Middle Eastern lineages in Indian Muslim populations. Eur J Hum Genet 2010;18: 354-363.

44 Behar DM, Hammer MF, Garrigan D, Villems R, Bonne-Tamir B, Richards M, Gurwitz D, Rosengarten D, Kaplan M, Della Pergola S, Quintana-Murci L, Skorecki K: MtDNA evidence for a genetic bottleneck in the early history of the Ashkenazi Jewish population. Eur J Hum Genet 2004;12:355364.

45 Gonzalez AM, Larruga JM, Abu-Amero KK, Shi Y, Pestano J, Cabrera VM: Mitochondrial lineage M1 traces an early human backflow to Africa. BMC Genomics 2007;8:223.

46 Boyce M: A History of Zoroastrianism - The Early Period. London, Brill Academic Publications, 1996

47 Gao S, Cui Y, Yang Y, Duan R, Abuduresule I, Mair VH, Zhu H, Zhou H: Mitochondrial DNA analysis of human remains from the Yuansha site in Xinjiang. Sci China C Life Sci 2008;51:205-213.

48 Lamberg-Karlovsky CC: Archaelogy and Language: the Indo-Iranians. Curr Anthropol 2002;43:63-88.

49 Cerný V, Pereira L, Kujanová M, Vasíková A, Hájek M, Morris M, Mulligan CJ: Out of Arabia-the settlement of Island Soqotra as revealed by mitochondrial and Y chromosome genetic diversity. Am J Phys Anthropol 2009; 138:439-447. 